\title{
Latitudinal trait variation and responses to drought in Arabidopsis lyrata
}

\author{
Antoine Paccard · Alexandre Fruleux $\cdot$ Yvonne Willi
}

Received: 16 October 2013 / Accepted: 10 March 2014 / Published online: 6 April 2014

(C) Springer-Verlag Berlin Heidelberg 2014

\begin{abstract}
Species may respond in three ways to environmental change: adapt, migrate, or go extinct. Studies of latitudinal clines can provide information on whether species have adapted to abiotic stress such as temperature and drought in the past and what the traits underlying adaptation are. We investigated latitudinal trait variation and response to drought in North American populations of Arabidopsis lyrata. Plants from nine populations collected over $13^{\circ}$ latitude were grown under well-watered and dry conditions. A total of 1,620 seedlings were raised and 12 phenological, physiological, morphological, and life history traits were measured. Two traits, asymptotic rosette size and the propensity to flower, were significantly associated with latitude: plants from northern locations grew to a larger size and were more likely to flower in the first season. Most traits displayed a plastic response to drought, but plasticity was never related linearly with latitude nor was it enhanced in populations from extreme latitudes with reduced water availability. Populations responded to drought by adopting mixed strategies of resistance, tolerance, and escape. The study shows that latitudinal adaptation in $A$. lyrata involves the classic life history traits, size at and timing
\end{abstract}

Communicated by Christina Marie Caruso.

Electronic supplementary material The online version of this article (doi:10.1007/s00442-014-2932-8) contains supplementary material, which is available to authorized users.

A. Paccard $(\varangle) \cdot$ A. Fruleux $\cdot$ Y. Willi

Evolutionary Botany, Institute of Biology, University

of Neuchâtel, Rue Emile-Argand 11, 2000 Neuchâtel,

Switzerland

e-mail: antoine.paccard@mcgill.ca

A. Paccard

Redpath Museum and Department of Biology, McGill University,

859 Sherbrooke Street West, Montreal, QC, H3A 0C4, Canada of reproduction. Contrary to recent theoretical predictions, adaptation to margins is based on fixed trait differences and not on phenotypic plasticity, at least with respect to drought.

Keywords Environmental change - Latitudinal cline · Phenotypic plasticity $\cdot$ Drought resistance .

Drought tolerance

\section{Introduction}

Climate change will have major impacts on species, and it is therefore essential to study the ability of populations to cope with rapid habitat modifications (Davis and Shaw 2001; Jump and Peñuelas 2005; Parmesan 2006). When species face environmental change, they may respond in three different ways: shift their geographic distribution, adapt, or go extinct locally (Lynch and Lande 1993; Bell and Collins 2008). Many organisms are unlikely to change their distribution rapidly because of limited dispersal ability [e.g., many herbaceous plants (Vekemans and Hardy 2004)]. Thus, local persistence depends on the ability to show immediate adaptive phenotypic or microevolutionary responses to change. Studying evolution over a specieswide latitudinal cline can help us understand how populations have adapted to climatic differences in the past and which traits may be limited in their adaptation to future climate change. This approach is known as "space-for-time substitution" (Pickett 1989), where current spatial differences in climate are used to predict the traits that are likely to be under selection under future climate change.

The evolution of adaptive population differences along a cline depends on several factors. The long-term selection response is positively dependent on the intensity and duration of selection (Robertson 1960; Wei et al. 1996), 
although in natural populations consistency in the direction of selection is possibly more important (e.g., Grant and Grant 2002). Long-term selection response is also positively associated with the standing genetic variance and the new mutational variance in the trait (Robertson 1960; Hill and Rasbash 1986a, b; Wei et al. 1996). Population size is relevant because it is positively related to the probability of fixation of beneficial standing and new genetic variance (Robertson 1960; Hill and Rasbash 1986a, b; Wei et al. 1996). Gene flow along the cline between similar selection regimes enhances the rate of adaptation, but dispersal from sites with different selection regimes can import maladapted genes and thereby swamp local adaptation (reviewed in Bridle and Vines 2007). The key factors limiting adaptation to edges of clinal distributions include steep environmental gradients, small population size, and asymmetric gene flow from high-quality core habitats (Bridle and Vines 2007; Kawecki 2008). In practice, though, gene flow over large geographic distances may be not important in many species (Vekemans and Hardy 2004; Jenkins et al. 2010).

Adaptation along a climate gradient could involve evolution of enhanced phenotypic plasticity within marginal habitats. Chevin and Lande (2011) developed models to explore the evolution of trait plasticities under source-sink conditions and along a cline connected by gene flow. The results confirmed that when plasticity can evolve, local adaptation within a marginal sink habitat is more likely, at least under moderate divergent selection. And plasticity can evolve to be higher at the ends of a cline under certain conditions; this diminishes the extent of maladaptation, increases population size, and may increase the size of the species' geographic range. Thus, variation among populations in trait plasticities, in addition to trait means, should be expected along climate gradients. Such plasticity would be additional to plasticity that may contribute to population persistence along a cline without any adaptation occurring.

Expression of most traits is highly dependent on the environment and therefore must be studied using common environment experiments. If significant differences among populations correlate with environmental conditions of the source sites, we can assume that shifts arose from adaptive evolution. Studies comparing populations from different latitudes in common environments observe that phenological, physiological, morphological, and life history traits can correlate with latitude. In herbaceous plant and grass species, the most consistent variation occurs in reproductive development: plants from lower compared to higher latitudes often have a slower reproductive development (Etterson 2004; Griffith and Watson 2005; De Frenne et al. 2011; Edwards et al. 2011; Woods et al. 2012; Novy et al. 2013). In two Arabidopsis species, the trend is reported to be the opposite, with generally slower development in northern populations (Stinchcombe et al. 2004; Riihimäki

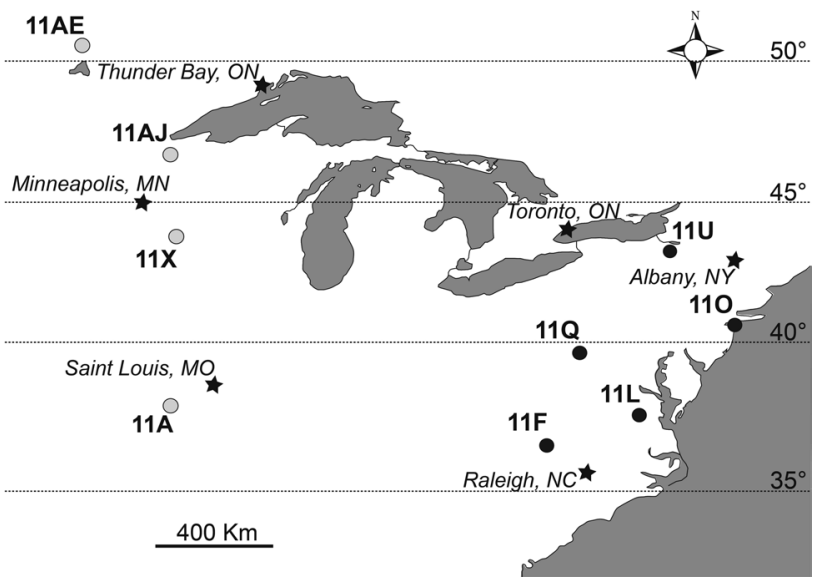

Fig. 1 Map showing the locations of Arabidopsis lyrata populations from western (grey circles) and eastern (black circles) latitudinal gradients in the USA and Canada

et al. 2005). Past studies have also found non-linear relationships between traits and latitude (Neuffer 2011) or that phenotypic plasticity varied with latitude (e.g., Etterson 2004; Maron et al. 2004, 2007; Riihimäki et al. 2005; De Frenne et al. 2011; Woods et al. 2012). However, Chevin and Lande's (2011) prediction of enhanced plasticity at distribution edges remains mostly untested.

We investigated patterns of variation in traits and plasticities along two latitudinal clines of the perennial plant Arabidopsis lyrata in North America. The nine populations covered a gradient of $13^{\circ}$ latitude that included southern and northern edges of the distribution (Fig. 1). Many components of climate are correlated with this latitudinal gradient. For example, temperature, precipitation, and wind speed decrease with latitude (USA National Weather Service; http://www.noaa.gov). Water availability is not linearly related with latitude but is lower at the southern and northern distribution edges (see "Results"). In this study, we exposed plants to well-watered and dry conditions, and evaluated latitudinal trends in 12 traits and their plasticities (Table 1). The traits were chosen because of their potential importance in coping with reduced water availability. Some were assumed to reflect resistance strategies to dry conditions by reducing stress ["dehydration avoidance" (Ludlow 1989)]. These included water-use efficiency (Farquhar et al. 1989; Knight et al. 2006), stomata density and length (Hetherington and Woodward 2003), leaf dissection (Nicotra et al. 2011), specific leaf area (Knight et al. 2006), leaf dry matter content (Cornelissen et al. 2003), and trichome density (Picotte et al. 2009). Other traits were assumed to reflect tolerance strategies under dry conditions that reduce the fitness consequences of stress ["dehydration tolerance" (Ludlow 1989)]. These included photosynthetic capacity, growth, size, and a switch to sexual reproduction. 
Table 1 Description of traits assessed in this study

\begin{tabular}{lll}
\hline Trait & Description & Units \\
\hline Time to germination & Time until cotyledons visible & Days \\
Germination rate & Fraction of seeds germinated per tub, binary & \\
Growth rate & Initial growth rate from logistic growth model & \\
Rosette size & Asymptotic rosette radius of logistic growth model & $\mathrm{mm}$ \\
Water-use efficiency, $\delta^{13} \mathrm{C}$ & ${ }^{13} \mathrm{C}:{ }^{12} \mathrm{C}$ ratio in leaves & $\%$ \\
Photosynthetic capacity, $\% \mathrm{~N}$ & Percent nitrogen in dried leaves & $\%$ \\
Stomata density & Stomata number per leaf sample area & $\mathrm{mm}^{-2}$ \\
Stomata length & Distance between guard cell junctions & $\mu \mathrm{m}$ \\
Leaf dissection index (DI) & Leaf dissection relative to a circle & \\
Specific leaf area & Area-to-dry weight ratio of leaf hole punch & $\mathrm{mm}^{2} \mathrm{mg}^{-1}$ \\
Leaf dry matter content & Dry-to-wet weight ratio of leaf hole punch & $\mathrm{mg} \mathrm{g}^{-1}$ \\
Trichome density & Trichome number per leaf hole punch & $\mathrm{mm}^{-2}$ \\
Flowering & Reproductive status at the end of study $(0 / 1)$ & \\
Time to flowering & Time from germination to flowering & $\mathrm{Days}^{-2}$ \\
\hline
\end{tabular}

The traits indicating tolerance in this study were not independent of resistance. The specific questions we addressed were: which traits are linearly or non-linearly associated with latitude? What are the plastic responses to drought? And, is phenotypic plasticity higher at range margins with reduced water availability?

\section{Materials and methods}

Sampling of populations

We sampled seeds from nine populations of Arabidopsis lyrata subsp. lyrata in 2011 from the USA and Southern Canada (Fig. 1; Appendix Table S1). The populations spanned most of the latitudinal extent of the species range in North America, which extends from Missouri and North Carolina in the south to Ontario and upstate New York/ Vermont in the north (Al-Shehbaz 2010; Y. Willi, personal observation). A related species, Arabidopsis arenicola, occurs farther north and northwest in Canada (Schmickl et al. 2010). Our samples included the full latitudinal range within two ancestral clusters of this subspecies (Willi and Määttänen 2010; Griffin and Willi 2014). The western cluster was represented by populations in Missouri, Iowa, Wisconsin, and Ontario (Lake of the Woods); the eastern cluster included populations from North Carolina, Virginia, Maryland, New Jersey, and upstate New York. All populations are predominantly outcrossing, based on their relatively high expected heterozygosity (range 0.25-0.61) and low fixation index $\left(F_{\text {IS }} \leq 0.07\right)$ (Willi and Määttänen 2011; Griffin and Willi 2014). For each population, mature fruits of 50 plants were sampled over a surface area of about $500 \mathrm{~m}^{2}$.

Environmental data for the sampling sites were extracted from two sources. Average spring temperature and average spring precipitation were calculated from the WorldClim database (Hijmans et al. 2005). We used data from springdefined as the months of April, May, and June-because that corresponds to the growing season of A. lyrata (AlShehbaz 2010). Spring-average actual evapotranspiration, average spring soil water stress, and the whole-year Priestley-Taylor $\alpha$ coefficient were calculated from a database maintained by the Consortium for Spatial Information (Trabucco and Zomer 2010; http://www.cgiar-csi.org/). Soil water stress expresses the fraction of soil water content available for evapotranspiration processes, and the Priestley-Taylor $\alpha$ coefficient is the ratio of actual to potential evapotranspiration, thereby reflecting the extent to which vegetation is affected by aridity stress. For both variables, lower values imply more water stress.

Experimental design and raising plants

We reared offspring from 30 spatially well-separated seed families per population under two watering treatments: wellwatered/wet and dry $(9$ populations $\times 30$ families $=270$ families +2 families to compensate for others with few seeds). A total of six individuals per maternal seed family were raised in three blocks, each containing one plant growing under wet conditions and one under dry conditions $(270$ families $\times 2$ treatments $\times 3$ blocks +80 extra plants of 10 families of one southern and one northern population-96 missing plants $=1,604$ plants). In each block, plants were randomly positioned within six trays per treatment, for a total of 36 trays. There were 54 pots per tray (diameter $4.3 \mathrm{~cm}$, volume $63 \mathrm{~cm}^{3}$; gvz-rossat, Otelfingen, Switzerland), each filled with a 1:1 mixture of sand and peat. We formed three small wells in the soil and sowed three seeds into them, to ensure that at the end we had at least one plant growing. The wells were positioned identically in every pot, 
so that the timing of germination could be attributed to a particular seedling. After sowing, trays were watered with Solbac organic solution in order to prevent the appearance of shoot- and leaf-eating fly larvae (Andermatt Biocontrol, Grossdietwil, Switzerland). Trays were then put in a cold chamber $\left(4{ }^{\circ} \mathrm{C}\right.$, dark) for 10 days of stratification and sprayed with tap water three times a week.

After stratification, we transferred the trays into three growth chambers (CLF Plant Climatics, Wertingen, Germany) with three levels each (top, middle, and bottom). These levels corresponded to the three blocks. Every week until the end of the experiment, we relocated blocks to a new randomly chosen level, and reassigned tray positions within blocks. Germination conditions were set to $8 \mathrm{~h}$ light $/ 16 \mathrm{~h}$ dark at $18{ }^{\circ} \mathrm{C}$ with a relative humidity of 40 $60 \%$. Light intensity was $150 \mu \mathrm{mol} \mathrm{m} \mathrm{m}^{-2} \mathrm{~s}^{-1}$ provided by a mixture of fluorescent lamps and red light-emitting diodes. Light conditions during germination were chosen to mimic late winter. In order to keep humidity high, trays were covered with a fine-mesh plastic cloth for the first 2 weeks (Windhager, Thalgau, Austria). Trays were sprayed from above every 1-3 days and watered with Solbac solution from the bottom once a week. We recorded germination three times a week and adjusted data for mid-interval time. After 17 days, by which time most seeds had germinated, we changed settings in two time steps to longer-day conditions, $14 \mathrm{~h} \mathrm{light}$ at $20^{\circ} \mathrm{C} / 10 \mathrm{~h}$ dark at $18{ }^{\circ} \mathrm{C}$, and a light intensity of $200-250 \mu \mathrm{mol} \mathrm{m}{ }^{-2} \mathrm{~s}^{-1}$. At the same time, we randomly removed all excess seedlings to leave one plant per pot; 48 excess plants were transplanted into pots with no germinated seedling.

Watering treatments were begun 1 month after the onset of germination. Initially, trays in the wet treatment were watered from the bottom twice a week with 11 of tap water, and trays in the dry treatment received 11 once a week. After 3 weeks, the drought treatment was changed to more severe. Plants were not watered until they began to wilt. Once we detected wilting, we gave $6 \mathrm{ml}$ of water per plant every other day for 3 weeks. Daytime temperature was increased to $22{ }^{\circ} \mathrm{C}$ to hasten the desiccation process. Regular measurements with a soil moisture meter $\left(\mathrm{ECH}_{2} \mathrm{O}\right.$; Decagon Devices, Pullman, USA) indicated that volumetric moisture content remained under $10 \%$ for the dry treatment and above $30 \%$ for the wet treatment.

\section{Trait measures}

\section{Growth}

Plants were photographed with a digital camera once a week for 7 weeks, starting just before the treatments began, to estimate growth trajectories. We used image analysis software [ImageJ version 1.44 (Rasband 2011)] to measure the average length of the two longest rosette leaves of each plant, which represented the rosette radius. The rosette radius of plants in eight trays was influenced by accidental exposure to $30 \mathrm{~h}$ of continuous light in week 2 , so data from these trays were adjusted to the means and SDs observed in non-exposed trays within the corresponding blocks and treatments.

We estimated growth and size of each plant from a logistic model fit to the seven observations of rosette radius. The two-parameter logistic emerged as the best of seven alternative growth models, including linear, exponential, power, two- and three-parameter logistic, von Bertalanffy, and Gompertz. Average Akaike information criterion weights were much higher for the two logistic models than for other models $(0.362$ for the two-parameter logistic and 0.307 for the three-parameter logistic), so we calculated growth rate and asymptotic size of the rosette radius for all plants from the two-parameter model. Parameter estimates for seven plants were discarded because at least one of the two parameters was more than 5 SDs larger than the mean. In these cases we accepted the rosette radius at the last round of photographs as the asymptotic size. Models were fit in R version 3.0.1 (R Core Team 2013) with the package drc (Ritz and Streibig 2005).

\section{Leaf physiological measures}

We measured the carbon stable isotope ratio $\left(\delta^{13} \mathrm{C}\right)$ as an estimate of integrated water-use efficiency (Farquhar and Richards 1984) and percent leaf nitrogen (\%N) as an estimate of photosynthetic capacity (Reich et al. 1997). All plants were well watered on the morning when we took samples or measured leaf traits, so that measurements were made on water-saturated tissue (Cornelissen et al. 2003); an exception were stomata measures. About $50 \mathrm{mg}$ of fresh leaf material per plant was collected and immediately dried in a lyophiliser for $24 \mathrm{~h}$ (Edwards Modulyo, West Sussex, England). A steel bullet was added to each sample, and samples were ground for $30 \mathrm{~s}$ (Mixer Mill MM 300; Retsch, Haan, Germany) and submitted for isotope mass spectrometry. This gave the $\% \mathrm{~N}$, and the $\mathrm{C}$ isotope ratio $\left({ }^{13} \mathrm{C}:{ }^{12} \mathrm{C}\right)$ of the sample $\left(R_{\mathrm{s}}\right)$ relative to that of the reference $\left(R_{\mathrm{PDB}}\right), \delta^{13} \mathrm{C}=\left(R_{\mathrm{s}} / R_{\mathrm{PDB}}-1\right) \times 1,000 \%$ (Farquhar et al. 1989), where PDB is Pee Dee belemnite. We corrected $\delta^{13} \mathrm{C}$ data for the ambient ${ }^{13} \mathrm{C}:{ }^{12} \mathrm{C}$ ratio by subtracting the average $\delta^{13} \mathrm{C}$ obtained from eight corn plants $(-13.82 \%$ ), which were raised over the treatment period with the experimental plants, distributed over the three blocks. Corn does not discriminate between the two $\mathrm{C}$ isotopes, which makes it a useful reference for the ambient ${ }^{13} \mathrm{C}:{ }^{12} \mathrm{C}$ ratio.

\section{Stomata density and stomata length}

We measured stomata on one fully extended and hardened leaf per plant. Using clear nail varnish, we polished a small 
portion of the abaxial side of the leaf and let it dry for $5 \mathrm{~min}$. Once dried, we used a small piece of clear tape to remove the polished portion, and then affixed the tape to a microscope slide. Stomata impressions, visible on the dried nail varnish, were photographed at $\times 100$ magnification (Leitz Diaplan; Leica Microsystems, Wetzlar, Germany) and analyzed using ImageJ. Stomata density $\left(\mathrm{mm}^{-2}\right)$ was assessed over a surface of $206,822 \mu \mathrm{m}^{2}$. Stomata length $(\mu \mathrm{m})$ was the average distance between the guard cell junctions of ten stomata (Maherali et al. 2002). We ensured that measurements were made on stomata of about the same age by considering the average size of the stomata and the surrounding epidermis cells.

\section{Leaf dissection index}

Two fully extended leaves per plant were scanned and analyzed using ImageJ to obtain leaf perimeter and leaf area. Leaf dissection index (DI) was calculated by Fourier transformation, DI $=$ perimeter $/[2 \sqrt{ }($ area $\times \pi)]$ (Kincaid and Schneider 1983). Values are unitless and are expressed relative to a circle with a DI of 1 . Analysis was performed on averages of the two leaves.

\section{Specific leaf area and leaf dry matter content}

A $24-\mathrm{mm}^{2}$ disc was punched along the central vein of the leaf blade at the distal end of two fully extended leaves. For the smallest leaves, we used a hole punch of $7 \mathrm{~mm}^{2}$. The discs were immediately weighed to the nearest $0.1 \mathrm{mg}$, placed into an unbleached paper bag, dried in an oven at $60{ }^{\circ} \mathrm{C}$ for $48 \mathrm{~h}$, and then weighed again. Specific leaf area and leaf dry matter content were calculated as area over dry weight $\left(\mathrm{mm}^{2} \mathrm{mg}^{-1}\right)$ and dry weight over fresh weight $\left(\mathrm{mg} \mathrm{g}^{-1}\right)$, respectively (Cornelissen et al. 2003). Analyses were performed on plant means.

\section{Trichome density}

Trichome density was the total number of trichomes on the two discs of a plant divided by their area. Counting was done just before the discs were dried, directly after measuring wet weight. Analysis was performed on plant means.

\section{Flowering status and flowering time}

With few exceptions, plants started flowering only at the end of the 6-week treatment period. We recorded the day of first flower opening every 2-3 days throughout the flowering period. Flowering time was calculated as the number of days between germination and the appearance of the first flower, both interpolated to the mid-point between adjacent checks. For those plants that were about to flower at the end of the experiment, 213 days after the end of stratification, flowering date was estimated by adding 2 days for the nine plants with flower buds, 7 days for the 49 bolted plants with one stem $\geq 2 \mathrm{~cm}$, and 20 days for the 20 bolted plants with shorter stems. Flowering status was defined as "no" for plants that had not bolted by day 213, and "yes" for plants that had bolted.

\section{Statistical analyses}

Correlations between latitude and the environmental variables were inspected to ascertain the climatic implications of the latitudinal gradient. We explored the effects of region, latitude, and treatment on phenotypic data in a hierarchical mixed model [Singer 1998; GLIMMIX procedure in SAS (SAS Institute 2002)]. Random effects were plant nested within family and population at the first level, family nested within population at the second level, and population at the third level. The model for the trait of time of germination had one lower random effects level, seed nested within tub, family and population. Treatment was a fixed effect on the level of the plant, and region and latitude were fixed effect on the level of the population. Latitude was centered to a mean of 0 . Random effects were estimated by restricted maximum likelihood or residual pseudo-likelihood (binary variables), assuming a one-banded variance-covariance matrix. Normality of the residuals was improved by $\log$ transformation of timing of germination, percent leaf $\mathrm{N}$, specific leaf area, and trichome density, and all continuous traits were corrected for tray effect within treatment. Germination rate and flowering status were binary variables, assigned the value 0 when not all seeds germinated or there was no sign of bolting by the end of the experiment.

We explored geographic patterns in trait plasticity using hierarchical mixed-model analysis with the random effects of family nested within population at the first level, and population at the second level. Latitude and its square term were predictor variables on the level of the population and were centered to a mean of 0 . Plasticity was defined as the change in the trait value under dry conditions relative to that in the wet treatment. This was calculated as log-transformed family mean values under dry minus logtransformed family mean values under wet. We worked with signed instead of absolute plasticity values because Chevin and Lande's (2011) model predicts the evolution of adaptive plasticity, which implies directional change. This approach is valid even in the absence of information about the direction of the adaptive response to drought. Growth rate and leaf DI were not transformed as they were already on a scale of proportional change. For flowering status, family mean values were often 0 , so plasticity was simply the difference between treatments. All continuous traits were corrected for tray effect within treatment, and plasticity data were corrected for region. 
Table 2 Results of mixedmodel analyses testing the effect of region, source latitude, and treatment (dry vs. wet) on all traits

Values reported are sample size $(n)$ and $F$-value for each trait. Random effects are not shown

$n$ Number of seeds (for germination) or plants (all other traits)

$\dagger P<0.1, * P<0.05$,

** $P<0.01, * * * P<0.001$

\begin{tabular}{llllll}
\hline Trait & $n$ & Region & Latitude $(\mathrm{L})$ & Treatment $(\mathrm{T})$ & $\mathrm{L} \times \mathrm{T}$ \\
\hline$d f_{\text {numerator }}, d f_{\text {denominator }}$ & & 1,6 & 1,6 & 1,8 & $1, n-11$ \\
Time to germination & 4,005 & $12.14^{*}$ & 1.61 & & \\
Germination rate & 1,700 & $7.32^{*}$ & 0.09 & & \\
Growth rate & 1,594 & 0.01 & 0.02 & $39.67^{* * *}$ & 0.64 \\
Asymptotic rosette size & 1,595 & $8.16^{*}$ & $6.36^{*}$ & $32.38^{* * *}$ & 1.40 \\
Water-use efficiency $\left(\delta^{13} \mathrm{C}\right)$ & 1,555 & 0.72 & 3.14 & $215.29^{* * *}$ & 0.13 \\
Photosynthetic capacity $(\% \mathrm{~N})$ & 1,554 & $5.53^{\dagger}$ & 2.31 & $225.24^{* * *}$ & 0.17 \\
Stomata density & 1,409 & 0.30 & 0.06 & 1.07 & 0.50 \\
Stomata length & 1,424 & 0.98 & 0.16 & $26.79^{* * *}$ & 0.02 \\
Leaf DI & 1,557 & 0.62 & 1.14 & 2.86 & 0.74 \\
Specific leaf area & 1,563 & $7.29 *$ & 2.40 & 0.00 & 0.23 \\
Leaf dry matter content & 1,563 & 0.88 & 0.26 & $14.91^{* *}$ & 0.24 \\
Trichome density & 1,563 & 1.95 & 1.24 & $27.76^{* * *}$ & 0.47 \\
Flowering & 1,514 & 1.19 & $6.85^{*}$ & 0.32 & 0.01 \\
Time to flowering & 911 & 0.03 & 0.42 & $4.86^{\dagger}$ & 0.80 \\
\hline
\end{tabular}

\section{Results}

Latitude and climatic variables

Latitude was strongly correlated with average spring climatic variables (Appendix Table S2). High-latitude sites had lower temperature, lower precipitation, and lower actual evapotranspiration. Net water availability, measured by the difference between precipitation and actual evapotranspiration, was highest at about $43^{\circ} \mathrm{N}$ latitude, and lowest at the edges of the gradient (Appendix Fig. S1). Effects of latitude (estimate $=22.30, F=7.52, P=0.04$ ) and its square term (estimate $=-0.26, F=7.16, P=0.04$ ) were both significant. Thus, the driest conditions are experienced by plants from the northern and especially southern distribution margins. However, for both spring soil water stress and the Priestley-Taylor $\alpha$ coefficient depicting the ratio of actual to potential evapotranspiration, there was neither a simple correlation (Appendix Table S2) nor any indication of a quadratic relationship with latitude $(P>0.3)$.

\section{Latitude and trait means}

Mixed-model analyses showed that five traits differed between the two regions (Table 2). Eastern populations germinated earlier, had a higher germination rate, grew to larger asymptotic rosette size (Fig. 2a, b), tended to have lower leaf $\% \mathrm{~N}$, and had smaller specific leaf area (back-transformed least-squares mean $\pm \mathrm{SE}$ for east/west, time to germination $5.7 \pm 1.1 / 10.1 \pm 1.1$ days; germination rate $0.9 \pm 0.3 / 0.3 \pm 0.3$; asymptotic rosette radius $52.4 \pm 2.2 / 41.7 \pm 2.7 \mathrm{~mm} ; \% \mathrm{~N} 1.3 \pm 1.0 / 1.6 \pm 1.0 \%$; specific leaf area $10.8 \pm 1.0 / 12.1 \pm 1.0 \mathrm{~mm}^{2} \mathrm{mg}^{-1}$ ). Only two traits showed a significant relation with latitude, asymptotic rosette size and the propensity to flower by the end of the experiment (Table 2). Plants from northern latitudesindependent of region - had larger asymptotic rosette sizes (Fig. 2a, b) and were more likely to flower (Fig. 2c). Treatment significantly affected growth rate, asymptotic size of the rosette, $\delta^{13} \mathrm{C}, \% \mathrm{~N}$, stomata length, leaf dry matter content, trichome density, and-as a trend-flowering time (Table 2). Under dry conditions, plants had a relatively fast initial growth but grew to a smaller size, had higher values of $\delta^{13} \mathrm{C}$ and $\% \mathrm{~N}$, shorter stomata, higher leaf dry matter content, more trichomes, and flowered slightly earlier (Fig. 3). Leaf $\% \mathrm{~N}$ and $\delta^{13} \mathrm{C}$ were not correlated within treatments (wet, $n=764, r=-0.01, P>0.8$; dry, $n=790, r=-0.04$, $P>0.2$ ). None of the traits showed any interaction between latitude and treatment (Table 2). Models including the square term of latitude revealed no support for non-linear relationships along the latitudinal gradient $(P>0.4$, except for germination rate $P=0.09$ ).

Latitude and phenotypic plasticity

Family-level plasticity was significantly related to latitude and its square term for only one of the 12 traits assessed, leaf DI (Table 3). The plastic response switched sign between the edges and the center of distribution (Fig. 4), following the pattern of net water availability (Appendix Fig. S1). Leaves of populations at the edge of the distribution (where water availability is low) were less dissected in the dry than wet treatment, whereas leaves of populations from the center of the range (higher water availability) were slightly more dissected under dry than wet conditions. There were weak curvilinear relationships with latitude in plasticity in trichome density and in the propensity to flower in the first year. The increase in trichome density 

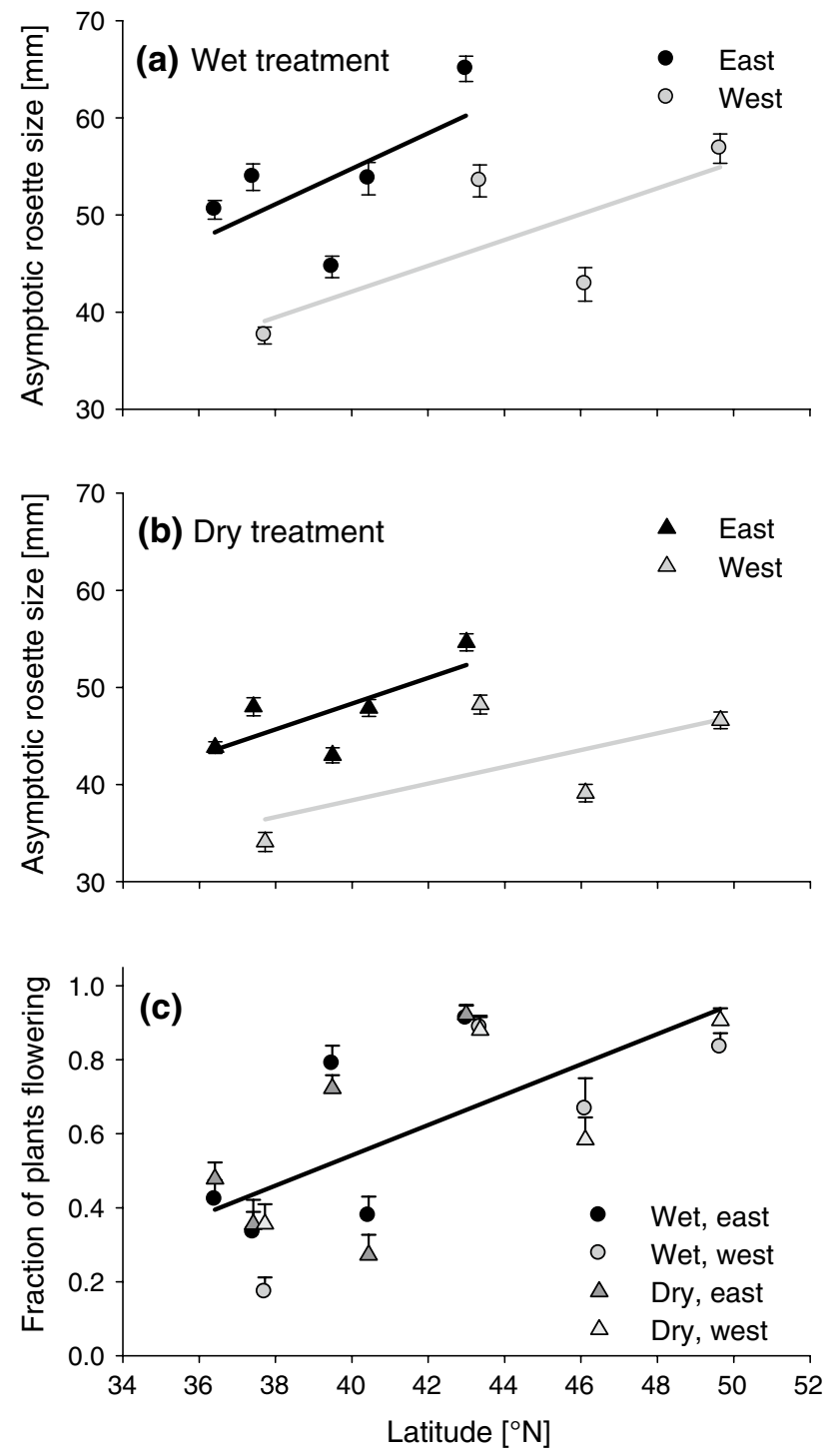

Fig. 2 Relationship between latitude and asymptotic rosette size in a the wet treatment and $\mathbf{b}$ the dry treatment, and relationship between latitude and $\mathbf{c}$ fraction of plants flowering in A. lyrata. Symbols depict population means ( \pm SE based on family means within treatments). c Symbols indicate treatment (wet or dry) and region. Lines indicate significant relationships. See Table 2 for statistics

under drought was less pronounced at latitudinal extremes than at mid-latitudes. Plants were more or equally likely to flower under drought than under wet conditions at latitudinal extremes, while mid latitude populations were less likely to flower under drought.

\section{Discussion}

Ascertaining traits important for climate adaptation is a first step in developing evolutionary ecological models predicting the fate of populations and species under climate change
(Hoffmann and Willi 2008; Willi and Hoffmann 2009). In this study, populations of Arabidopsis lyrata differed across latitude in both vegetative plant size and the propensity to flower in the first year-independent of treatment (Fig. 2). Other traits showed no association with latitude, i.e., phenological traits such as timing of germination and flowering, physiological traits such as $\delta^{13} \mathrm{C}$ reflecting water-use efficiency and leaf $\% \mathrm{~N}$ reflecting photosynthetic capacity, and morphological traits such as stomata density, stomata length, leaf dissection, specific leaf area, leaf dry matter content, and trichome density. Although plastic responses to experimental drought were strong for many traits, plasticity was approximately constant across the latitudinal gradient. Leaf DI was the only trait that showed differential plasticity between the center and edges of the latitudinal range. At latitudinal extremes with lower net water availability, leaves were less dissected under dry compared to wet conditions, whereas at mid-latitudinal sites with higher net water availability, leaves were slightly more dissected under dry conditions. Overall, though, our results do not suggest that plasticity is enhanced towards range margins.

In a common environment, systematic differences in trait expression among populations originating along an environmental gradient can be interpreted as arising from genetic differences caused by past evolutionary change. Because plants in this experiment were raised from fieldcollected seeds, non-genetic maternal environmental effects may contribute to population divergence. However, the trait differences that we observed were expressed well after germination and are therefore unlikely to be strongly affected by maternal environmental effects (e.g., El-Keblawy and Lovett-Doust 1999). Also, a previous study on one population of A. lyrata revealed that seed size did not correlate with a subset of the traits studied here (Paccard et al. 2013). Our results therefore suggest that plant adult size and reproductive development are traits that have genetically diverged along the latitudinal gradient.

Plants from the north grew to a larger size and were more likely to switch to flowering. The latter result agrees with a pattern observed in other studies, that reproductive development is the one trait that is consistently slower at low latitude in herbaceous plant and grass species (Etterson 2004; Griffith and Watson 2005; De Frenne et al. 2011; Edwards et al. 2011; Woods et al. 2012; Novy et al. 2013). Two Arabidopsis species may be exceptions. Arabidopsis thaliana from low latitudes were shown to have accelerated development to flowering, at least under a specific genetic background (Stinchcombe et al. 2004). European A. lyrata petraea from northern populations appeared to have a lower likelihood of flowering in a common garden experiment, but flowering propensity increased under longer day conditions in northern populations while it declined in southern populations (Riihimäki et al. 2005). Previous studies are more 

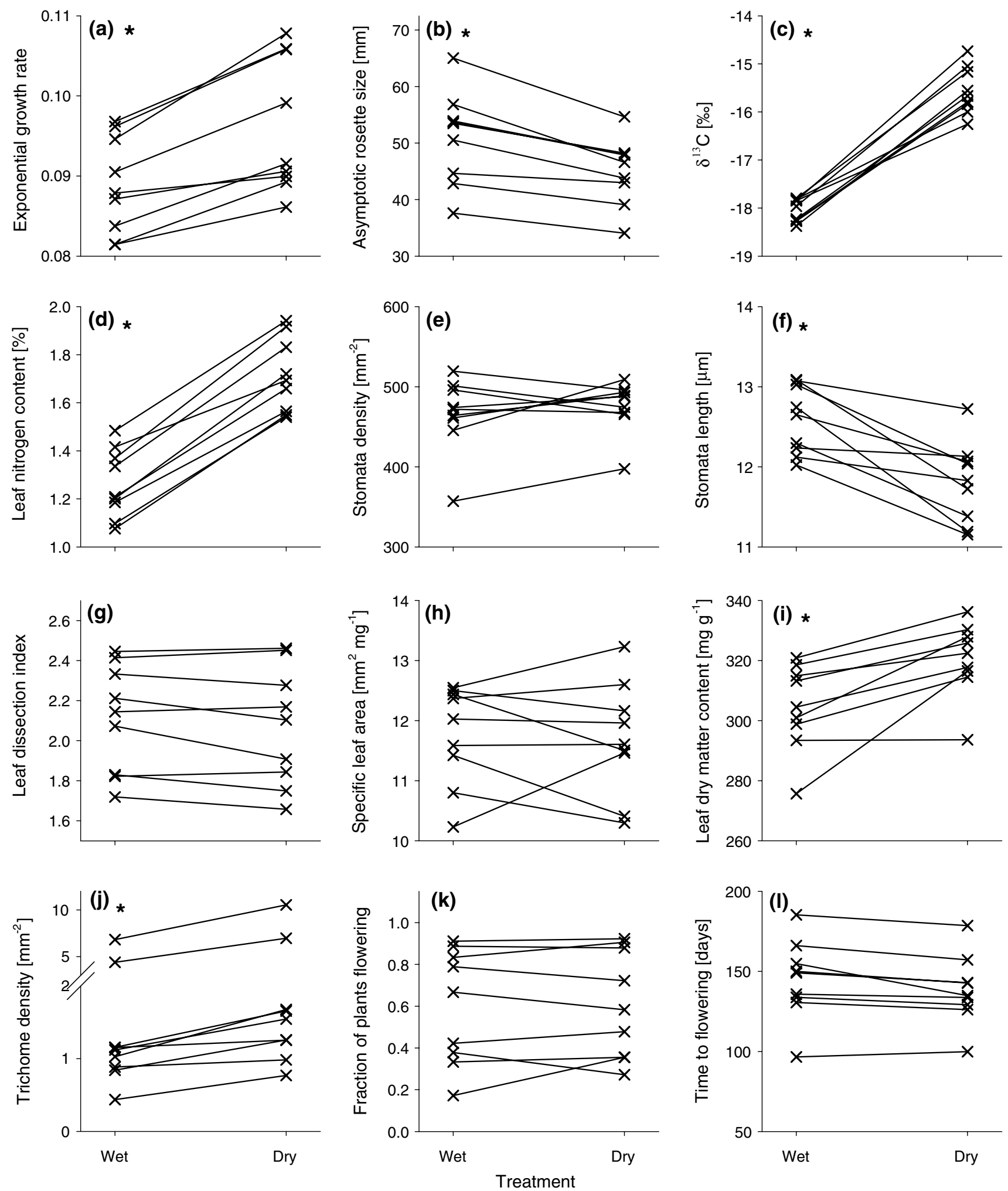

Fig. 3 Mean performance of A. lyrata populations under wellwatered (wet) and dry treatments. Symbols indicate population means (based on family means) within treatments; lines connect popula- tion response to treatments. Asterisk indicates a significant treatment effect. See Table 2 for statistics. All variables are untransformed 
Table 3 Results of analyses examining the effect of latitude on phenotypic plasticity in response to the dry treatment

\begin{tabular}{lccc}
\hline Trait & $n$ & $\begin{array}{l}\text { Latitude } \\
F\end{array}$ & $\begin{array}{l}\text { Latitude }^{2} \\
F\end{array}$ \\
\hline Growth rate & 257 & 0.65 & 0.57 \\
Asymptotic rosette size & 257 & 1.36 & 1.46 \\
Water-use efficiency, $\delta^{13} \mathrm{C}$ & 256 & 0.48 & 0.46 \\
Photosynthetic capacity, \%N & 256 & 0.12 & 0.13 \\
Stomata density & 257 & 0.48 & 0.45 \\
Stomata length & 257 & 0.14 & 0.12 \\
Leaf DI & 257 & $10.73^{*}$ & $10.30^{*}$ \\
Specific leaf area & 257 & 0.00 & 0.01 \\
Leaf dry matter content & 257 & 0.24 & 0.23 \\
Trichome density & 257 & $4.54^{\dagger}$ & $4.17^{\dagger}$ \\
Flowering & 257 & $4.05^{\dagger}$ & $3.79^{\dagger}$ \\
Time to flowering & 190 & 3.61 & 3.38 \\
\hline
\end{tabular}

Sample size $(n)$ is the number of seed families. $F$-values for latitude and latitude ${ }^{2}$ are given. Numerator and denominator $d f$ were 1,6 for both variables. Random effects are not shown

Plasticity was estimated as the change in the family mean trait value under dry conditions relative to that in the wet treatment (see "Materials and methods")

$\dagger P<0.1, * P<0.05$

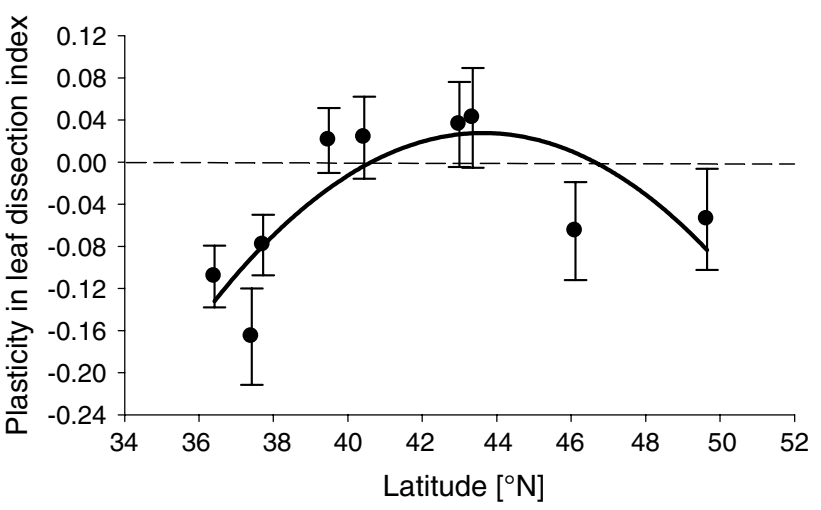

Fig. 4 The relationship between latitude and plastic response in leaf dissection index to the dry treatment among A. lyrata populations. Symbols depict population means ( \pm SE based on family values). Solid line depicts the significant linear and quadratic relationship with latitude; dashed line represents no plastic response. See Table 3 for statistics

ambiguous about latitudinal population differences in plant size. Northern populations of other species sometimes have fewer leaves or reduced aboveground biomass (Etterson 2004; Travis and Grace 2010; Woods et al. 2012; Novy et al. 2013), and in other cases have more aboveground growth (Griffith and Watson 2005; Maron et al. 2007; De Frenne et al. 2011). Large size and higher propensity to flower in the first year may not be independent traits, but may both reflect an underlying more rapid development in the north.
This is likely to be adaptive under the shorter growing season, reduced longevity, or generally more adverse growing conditions in the north [i.e., counter-gradient selection (Conover and Schultz 1995; Conover et al. 2009)].

The drought treatment induced plasticity in many traits (Fig. 3). Our study did not evaluate relationships between phenotype and fitness, and therefore we cannot address whether observed plasticity was adaptive. However, plastic responses were mostly consistent with an adaptive interpretation suggested by other work, and were similar to those found in a previous study of one population of A. lyrata (Paccard et al. 2013). The increased $\delta^{13} \mathrm{C}$ values under water stress suggest reduced stomata opening and water loss by transpiration (Farquhar et al. 1989), and higher leaf $\% \mathrm{~N}$ implies higher photosynthetic capacity (Reich et al. 1997). Plants developed shorter stomata in the dry treatment, which are known to close faster and reduce water loss under drought (Hetherington and Woodward 2003). Traits for which an adaptive interpretation of plasticity is less clear include the higher leaf dry matter content, which simply reflects reduced water content in water-stressed plants. Higher trichome density is thought to promote the maintenance of a boundary layer of elevated moisture between the inner portion of the leaf and the air, thereby reducing water loss (Picotte et al. 2009). In two other subspecies of Arabidopsis lyrata, Arabidopsis lyrata kamchatica and Arabidopsis lyrata petraea, trichomes were also suggested to help plants cope with drought (Steets et al. 2010; Sletvold and Ågren 2012). A shorter time to flowering has been shown to be adaptively favored as a drought escape strategy (Franks and Weis 2008). The functional explanations for accelerated growth rate and reduced size at reproduction in the dry treatment may be similar.

North American A. lyrata is highly adapted to cope with dry conditions. This is clearly visible in the combined results for water-use efficiency, photosynthetic capacity, and growth. Water-use efficiency (estimated by $\delta^{13} \mathrm{C}$ ) dramatically increased under drought in all populations, but photosynthetic capacity (estimated by leaf $\% \mathrm{~N}$ ) and initial growth rate also increased (Fig. 3). These results point toward both desiccation resistance and tolerance. The $\delta^{13} \mathrm{C}$ data indicate that stomata opening was reduced under drought, which is a resistance strategy, but tolerance is indicated by relatively high photosynthetic capacity and growth despite drought. The two measures of $\delta^{13}$ and leaf $\% \mathrm{~N}$ were not correlated. Additionally, the trend to flower slightly earlier in the dry treatment implies some ability to escape drought temporally. This result also contradicts the trade-off that has been suggested between flowering time and water-use efficiency (e.g., McKay et al. 2003). Mixed responses to drought involving resistance, tolerance, and escape are possible in A. lyrata and consistent with findings in other species (e.g., Wu et al. 2010). 
Chevin and Lande's (2011) model predicted that adaptation to distribution margins can involve phenotypic plasticity rather than phenotypically fixed differences. In our system, only one trait-leaf dissection-showed a non-linear relationship of plasticity with latitude. Plants originating from the northern and southern range margins reacted to drought by developing more rounded leaves, whereas those from the center of the distribution responded by developing slightly more dissected leaves. The adaptive basis of drought-induced "roundness" of leaves in edge populations may relate to lower net water availability near the range margins (Fig. S1). But overall, it was not generally true that plasticity increased at the margins. The model of Chevin and Lande (2011), like many other range margin models (reviewed in Kawecki 2008; Sexton et al. 2009), assumes some gene flow into the marginal populations. In herbaceous species such as A. lyrata, with little long-distance seed dispersal, this assumption is probably not fulfilled over large geographic ranges, and therefore gene flow is probably not of central importance in defining species traits, plasticities, and large-scale distribution limits.

We have shown that reproductive development and rosette size genetically vary with latitude, whereas other traits related to drought resistance do not. Although water availability is more limited at both ends of the latitudinal cline, there were no obvious relationships-neither linear nor quadratic-between the expression of traits reflecting drought resistance and latitude. This raises the question: do reproductive development and size harbor more genetic variation or are they less integrated and therefore adapt along the cline more readily than drought-resistance traits? To test this hypothesis, future studies should assess genetic variation of ecologically relevant traits and include traits linked to resistance to extreme temperatures. As temperature is linearly related to latitude, these traits can be expected to vary more linearly along the latitudinal gradient if they exhibit adaptive differences. This study also shows that A. lyrata, in contrast to A. thaliana, responds to drought stress with a mix of strategies of drought resistance, drought tolerance, and drought escape. Finally, our study showed that although drier conditions may be more common at the edges of species distribution, plastic responses to drought are not enhanced.

Acknowledgments Collection permits were granted by the US Army at Fort Leonard Wood, the Iowa State Preserves Advisory Board, the Iowa Department of Natural Resources, the Virginia Department of Conservation and Recreation, the Nature Conservancy of Maryland, the US National Park Service, and the New York State Office of Parks. Seeds at Fort Leonard Wood were kindly sampled by Joe Proffitt. We would like to thank the many people who helped with measuring plants, Olivier Bachmann, Emmanuel Bonjour, Benjamin Dauphin, Philippa Griffin, Adnan Peco, Marta Anda Perez, Katia Presani, Anouk Sarr, Reyhan Sonmez, and Julien Vieu. Josh Van Buskirk provided comments on the manuscript. Mass spectrometry was performed at the University of New Hampshire Stable Isotope Laboratory, Durham, NH, USA, and the Cornell University Stable Isotope Laboratory, Ithaca, NY, USA. The research was supported by the Swiss National Science Foundation (PP00P3-123396/1) and the Fondation Pierre Mercier pour la Science. The experiments were performed in Switzerland and comply with the current laws of this country.

\section{References}

Al-Shehbaz IA (2010) Magnoliophyta: Salicaceae to Brassicaceae. In: Flora of North America Editorial Committee (eds) Flora of North America north of Mexico. Oxford University Press, New York

Bell G, Collins S (2008) Adaptation, extinction and global change. Evol Appl 1:3-16

Bridle JR, Vines TH (2007) Limits to evolution at range margins: when and why does adaptation fail? Trends Ecol Evol 22:140-147

Chevin LM, Lande R (2011) Adaptation to marginal habitats by evolution of increased phenotypic plasticity. J Evol Biol 24:1462-1476

Conover DO, Schultz ET (1995) Phenotypic similarity and the evolutionary significance of countergradient variation. Trends Ecol Evol 10:248-251

Conover DO, Duffy TA, Hice LA (2009) The covariance between genetic and environmental influences across ecological gradients. Ann NY Acad Sci 1168:100-129

Cornelissen JHC, Lavorel S, Garnier E, Díaz S, Buchmann N, Gurvich DE, Reich PB, ter Steege H, Morgan HD, van der Heijden MGA, Pausas JG, Poorter H (2003) A handbook of protocols for standardised and easy measurement of plant functional traits worldwide. Aust J Bot 51:335-380

Davis MB, Shaw RG (2001) Range shifts and adaptive responses to quaternary climate change. Science 292:673-679

De Frenne P, Brunet J, Shevtsova A, Kolb A, Graae BJ, Chabrerie O, Cousins SAO, Decocq G, De Schrijver A, Diekmann M, Gruwez R, Heinken T, Hermy M, Nilsson C, Stanton S, Tack W, Willaert J, Verheyen K (2011) Temperature effects on forest herbs assessed by warming and transplant experiments along a latitudinal gradient. Glob Change Biol 17:3240-3253

Edwards KR, Bastlová D, Edwards-Jonášová M, Kvĕt J (2011) A comparison of univariate and multivariate methods for analyzing clinal variation in an invasive species. Hydrobiologia 674:119-131

El-Keblawy A, Lovett-Doust J (1999) Maternal effects in the progeny generation in zucchini, Cucurbita pepo (Cucurbitaceae). Int J Plant Sci 160:331-339

Etterson JR (2004) Evolutionary potential of Chamaecrista fasciculata in relation to climate change. I. Clinal patterns of selection along an environmental gradient in the Great Plains. Evolution 58:1446-1458

Farquhar GD, Richards RA (1984) Isotopic composition of plant carbon correlates with water-use efficiency of wheat genotypes. Aust J Plant Physiol 11:539-552

Farquhar GD, Ehleringer JR, Hubick KT (1989) Carbon isotope discrimination and photosynthesis. Annu Rev Plant Physiol Plant Mol Biol 40:503-537

Franks SJ, Weis AE (2008) A change in climate causes rapid evolution of multiple life-history traits and their interactions in an annual plant. J Evol Biol 21:1321-1334

Grant PR, Grant BR (2002) Unpredictable evolution in a 30-year study of Darwin's finches. Science 296:707-711

Griffin PC, Willi Y (2014) Evolutionary shifts to self-fertilization restricted to geographic range margins in North American Arabidopsis lyrata. Ecol Lett 17:484-490

Griffith TM, Watson MA (2005) Stress avoidance in a common annual: reproductive timing is important for local adaptation and geographic distribution. J Evol Biol 18:1601-1612 
Hetherington AM, Woodward FI (2003) The role of stomata in sensing and driving environmental change. Nature 424:901-908

Hijmans RJ, Cameron SE, Parra JL, Jones PG, Jarvis A (2005) Very high resolution interpolated climate surfaces for global land areas. Int J Climatol 25:1965-1978

Hill WG, Rasbash J (1986a) Models of long term artificial selection in finite population. Genet Res 48:41-50

Hill WG, Rasbash J (1986b) Models of long-term artificial selection in finite population with recurrent mutation. Genet Res 48:125-131

Hoffmann AA, Willi Y (2008) Detecting genetic responses to environmental change. Nat Rev Genet 9:421-432

Jenkins DG, Carey M, Czerniewska J, Fletcher J, Hether T et al (2010) A meta-analysis of isolation by distance: relic or reference standard for landscape genetics? Ecography 33:315-320

Jump AS, Peñuelas J (2005) Running to stand still: adaptation and the response of plants to rapid climate change. Ecol Lett 8:1010-1020

Kawecki TJ (2008) Adaptation to marginal habitats. Annu Rev Ecol Evol Syst 39:321-342

Kincaid DT, Schneider RB (1983) Quantification of leaf shape with a microcomputer and Fourier transform. Can J Bot 61:2333-2342

Knight CA, Vogel H, Kroymann J, Shumate A, Witsenboer H, Mitchell-Olds T (2006) Expression profiling and local adaptation of Boechera holboellii populations for water use efficiency across a naturally occurring water stress gradient. Mol Ecol 15:1229-1237

Ludlow MM (1989) Strategies of response to water stress. In: Kreeb KH, Richter H, Hinckley TM (eds) Structural and functional responses to environmental stresses: water shortage. SPB, the Hague, pp 269-281

Lynch M, Lande R (1993) Evolution and extinction in response to environmental change. In: Kareiva PM, Kingsolver JG, Huey RB (eds) Biotic interactions and global change. Sinauer, Sunderland, pp 234-250

Maherali H, Reid CD, Polley HW, Johnson HB, Jackson RB (2002) Stomatal acclimation over a subambient to elevated $\mathrm{CO}_{2}$ gradient in $\mathrm{a}_{3} / \mathrm{C}_{4}$ grassland. Plant Cell Environ 25:557-566

Maron JL, Vilà M, Bommarco R, Elmendorf S, Beardsley P (2004) Rapid evolution of an invasive plant. Ecol Monogr 74:261-280

Maron JL, Elmendorf SC, Vilà M (2007) Contrasting plant physiological adaptation to climate in the native and introduced range of Hypericum perforatum. Evolution 61:1912-1924

McKay JK, Richards JH, Mitchell-Olds T (2003) Genetics of drought adaptation in Arabidopsis thaliana. 1. Pleiotropy contributes to genetic correlations among ecological traits. Mol Ecol 12:1137-1151

Neuffer B (2011) Native range variation in Capsella bursa-pastoris (Brassicaceae) along a $2500 \mathrm{~km}$ latitudinal transect. Flora 206:107-119

Nicotra AB, Leigh A, Boyce CK, Jones CS, Niklas KJ, Royer DL, Tsukaya H (2011) The evolution and functional significance of leaf shape in the angiosperms. Funct Plant Biol 38:535-552

Novy A, Flory SL, Hartman JM (2013) Evidence for rapid evolution of phenology in an invasive grass. J Evol Biol 26:443-450

Paccard A, Vance M, Willi Y (2013) Weak impact of fine-scale landscape heterogeneity on evolutionary potential in Arabidopsis lyrata. J Evol Biol 26:2331-2340

Parmesan C (2006) Ecological and evolutionary responses to recent climate change. Annu Rev Ecol Evol Syst 37:637-669

Pickett STA (1989) Space-for-time substitution as an alternative to longterm studies. In: Likens GE (ed) Long-term studies in ecology: approaches and alternatives. Springer, New York Berlin Heidelberg, pp 110-135

Picotte JJ, Rhode JM, Cruzan MB (2009) Leaf morphological responses to variation in water availability for plants in the Piriqueta caroliniana complex. Plant Ecol 200:267-275
R Core Team (2013) R: a language and environment for statistical computing. R Foundation for Statistical Computing, Vienna

Rasband WS (2011) ImageJ. US National Institutes of Health, Bethesda, MD. http://imagej.nih.gov/ij/

Reich PB, Walters MB, Ellsworth DS (1997) From tropics to tundra: global convergence in plant functioning. Proc Natl Acad Sci USA 94:13730-13734

Riihimäki M, Podolsky R, Kuittinen H, Koelewijn H, Savolainen O (2005) Studying genetics of adaptive variation in model organisms: flowering time variation in Arabidopsis lyrata. Genetica 123:63-74

Ritz C, Streibig JC (2005) Bioassay analysis using R. J Stat Softw 12:1-22

Robertson A (1960) A theory of limits in artificial selection. Proc R Soc Lond B 153:234-249

SAS Institute (2002) SAS: version 9.2. SAS Institute, Cary, NC

Schmickl R, Jørgensen MH, Brysting AK, Koch MA (2010) The evolutionary history of the Arabidopsis lyrata complex: a hybrid in the amphi-Beringian area closes a large distribution gap and builds up a genetic barrier. BMC Evol Biol 10:98

Sexton JP, McIntyre PJ, Angert AL, Rice KJ (2009) Evolution and ecology of species range limits. Annu Rev Ecol Evol Syst 40:415-436

Singer JD (1998) Using SAS PROC MIXED to fit multilevel models, hierarchical models, and individual growth models. J Educ Behav Stat 24:323-355

Sletvold N, Ågren J (2012) Variation in tolerance to drought among Scandinavian populations of Arabidopsis lyrata. Evol Ecol 26:559-577

Steets JA, Takebayashi N, Byrnes JM, Wolf DE (2010) Heterogeneous selection on trichome production in Alaskan Arabidopsis kamchatica (Brassicaceae). Am J Bot 97:1098-1108

Stinchcombe JR, Weinig C, Ungerer M, Olsen KM, Mays C, Halldorsdottir SS, Purugganan MD, Schmitt J (2004) A latitudinal cline in flowering time in Arabidopsis thaliana modulated by the flowering time gene FRIGIDA. Proc Natl Acad Sci USA 101:4712-4717

Trabucco A, Zomer RJ (2010) Global soil water balance geospatial database. CGIAR Consortium for Spatial Information. Available at: http://www.cgiar-csi.org

Travis SE, Grace JB (2010) Predicting performance for ecological restoration: a case study using Spartina alterniflora. Ecol Appl 20:192-204

Vekemans X, Hardy OJ (2004) New insights from fine-scale spatial genetic structure analyses in plant populations. Mol Ecol 13:921-935

Wei M, Caballero A, Hill WG (1996) Selection response in finite populations. Genetics 144:1961-1974

Willi Y, Hoffmann AA (2009) Demographic factors and genetic variation influence population persistence under environmental change. J Evol Biol 22:124-133

Willi Y, Määttänen K (2010) Evolutionary dynamics of mating system shifts in Arabidopsis lyrata. J Evol Biol 23:2123-2131

Willi Y, Määttänen K (2011) The relative importance of factors determining genetic drift: mating system, spatial genetic structure, habitat and census size in Arabidopsis lyrata. New Phytol 189:1200-1209

Woods EC, Hastings AP, Turley NE, Heard SB, Agrawal AA (2012) Adaptive geographical clines in the growth and defense of a native plant. Ecol Monogr 82:149-168

Wu CA, Lowry DB, Nutter LI, Willis JH (2010) Natural variation for drought-response traits in the Mimulus guttatus species complex. Oecologia 162:23-33 